\title{
Introduction to the special issue "Palaeobotanical contributions in honour of Volker Mosbrugger"
}

\author{
Dieter Uhl ${ }^{1} \cdot$ Angela A. Bruch ${ }^{2} \cdot$ Torsten Utescher $^{1,3}$
}

Published online: 27 February 2021

(C) The Author(s) 2021

At the end of December 2020, Volker Mosbrugger retired, after 15 years, from his position as Director General of the Senckenberg Gesellschaft für Naturkunde, 2 years after he turned 65, the official age for retirement in Germany. During the last 40 years, Volker has built up an international reputation not only as a leading palaeobotanist, but also as a facilitator of science as well as a science politician.

This special issue is dedicated to Volker Mosbrugger (Fig. 1) as a scientist; thus, this introduction will focus mostly on his scientific career and achievements. There are many other aspects of Volker worthy to be honoured, but only listing his many scientific prizes and awards (which include the prestigious Gottfried Wilhelm Leibniz Prize awarded by the DFG in 1999, as well as an honorary doctorate in Lyon, France, and an honorary professorship in Jilin, China), memberships in academies, leading functions in large projects and scientific commissions, as well as his numerous positions for example in academic self-government, learned societies, and at Senckenberg, would fill several pages.

From 1973 to 1979, Volker, born in 1953 in the city of Konstanz at Lake Constance, studied biology and chemistry in Freiburg (Germany) and marine biology in Montpellier in France. After finishing his graduate studies in 1979, he

This is the editorial to the special issue "Palaeobotanical contributions in honour of Volker Mosbrugger"

Dieter Uhl

dieter.uhl@senckenberg.de

1 Senckenberg Forschungsinstitut und Naturmuseum Frankfurt, Senckenberganlage 25, 60325 Frankfurt am Main, Germany

2 ROCEEH Research Centre 'The Role of Culture in Early Expansions of Humans' of the Heidelberg Academy of Sciences, Senckenberg Forschungsinstitut und Naturmuseum Frankfurt, 60325 Frankfurt/ M, Germany

3 Institute for Geosciences, University of Bonn, Nussallee 8, 53115 Bonn, Germany worked in Freiburg with Dieter Vogellehner for his $\mathrm{PhD}$ in palaeobotany, which he received in 1983.

When looking at Volker's career from a scientific point of view, it can be subdivided in different, albeit overlapping phases in which he focussed on different topics. He graduated from Freiburg University with a thesis on Late Carboniferous plants and continued to work on this topic, especially on pecopterids, for his $\mathrm{PhD}$ (e.g. Mosbrugger 1983; Mosbrugger and Vogellehner 1986). Carboniferous plants remained a focus of his early career. During this phase, he already showed a liking for numerical approaches combined with hands on research on material as well as fieldwork (Fig. 2), which led him to biomechanics, the second large focus of his research (e.g. Mosbrugger 1990; Roth-Nebelsick et al. 2001). At the same time, this work sparked his interest in evolutionary theory (e.g. Mosbrugger 1988).

After finishing his $\mathrm{PhD}$, Volker went to Bonn University as an assistant to the late H.-J. Schweitzer and for his habilitation (Mosbrugger 1990), at that time a pre-condition to become a professor in Germany. During this period, Volker became more and more interested in research on Cenozoic environmental and climate change and was involved in the DFG funded Collaborative Research Centre "Interaction of continental material systems and their modelling" that further promoted his great interest in interdisciplinary research, processes and numeric modelling approaches (e.g. Steppuhn et al. 2006).

When Volker went to Tübingen as a professor in palaeontology in 1990, this topic became even more important, and he could convince numerous of his colleagues at Eberhard Karls University "to join forces", which led to the funding of a large collaborative research centre (Sonderforschungsbereich) "Climatically Coupled Processes in Mesozoic and Cenozoic Geo-Ecosystems" funded by the DFG, which ran from 1994 to 2001. A considerable milestone with respect to the quantitative reconstruction of palaeoclimates was the development of the Nearest Living Relative (NLR)-based Coexistence Approach (Mosbrugger and Utescher 1997; Utescher et al. 2014), an easy-to-apply, reliable and robust technique, that 

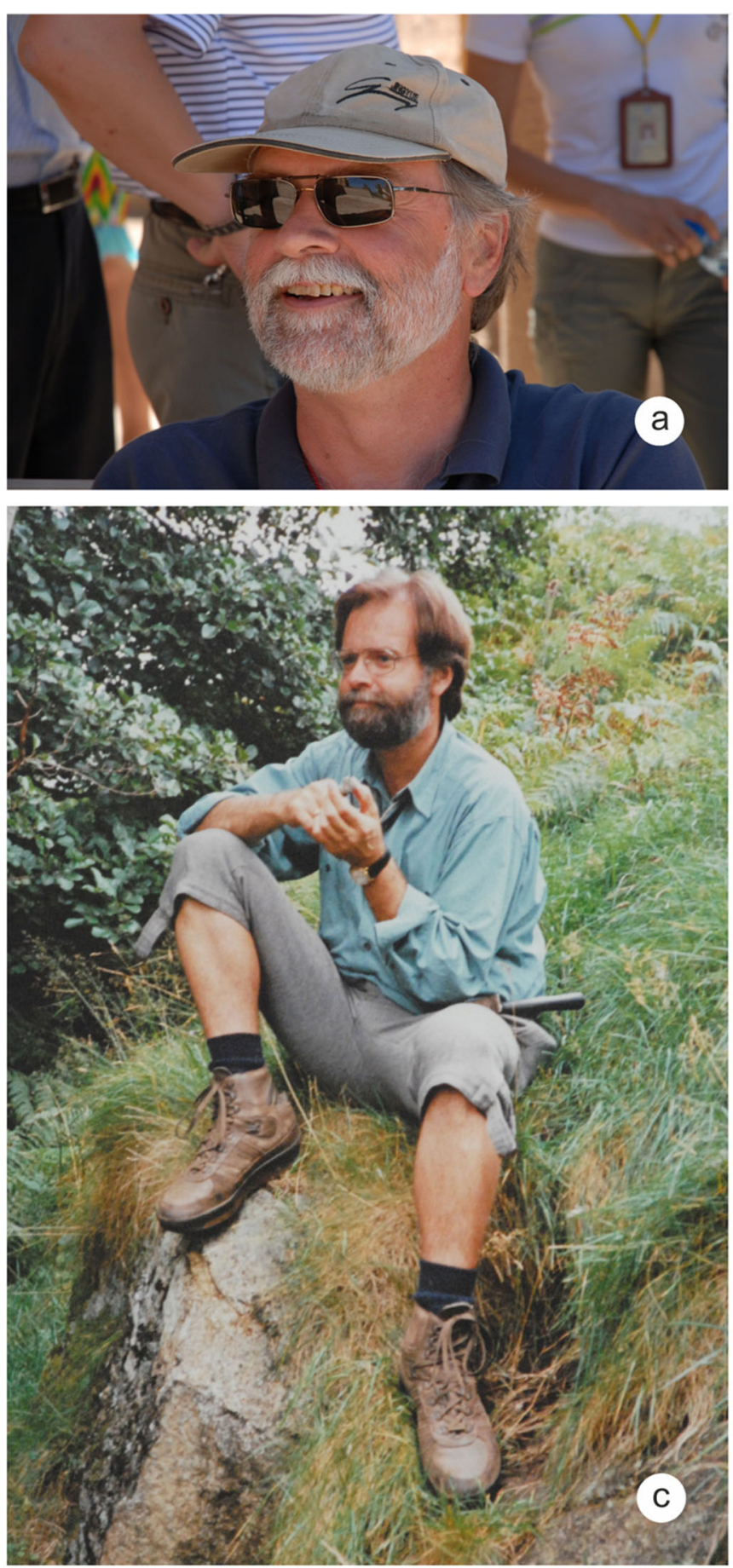

Fig. 1 Volker Mosbrugger. a Xinjiang, China, 2009 (photo: G. Mosbrugger); b opencast mine Hambach, Lower Rhine Embayment, Germany 1989 (photo: G. Mosbrugger); c Scotland, 1994 (photo: G.

has since then been applied successfully to literally hundreds of palaeofloras. Ever since its establishment, the database on which this technique is based on has been improved and despite some critiques on this method it is still one of the most successful techniques used for the reconstruction of palaeoclimatic parameters based on Cenozoic fossil plants.
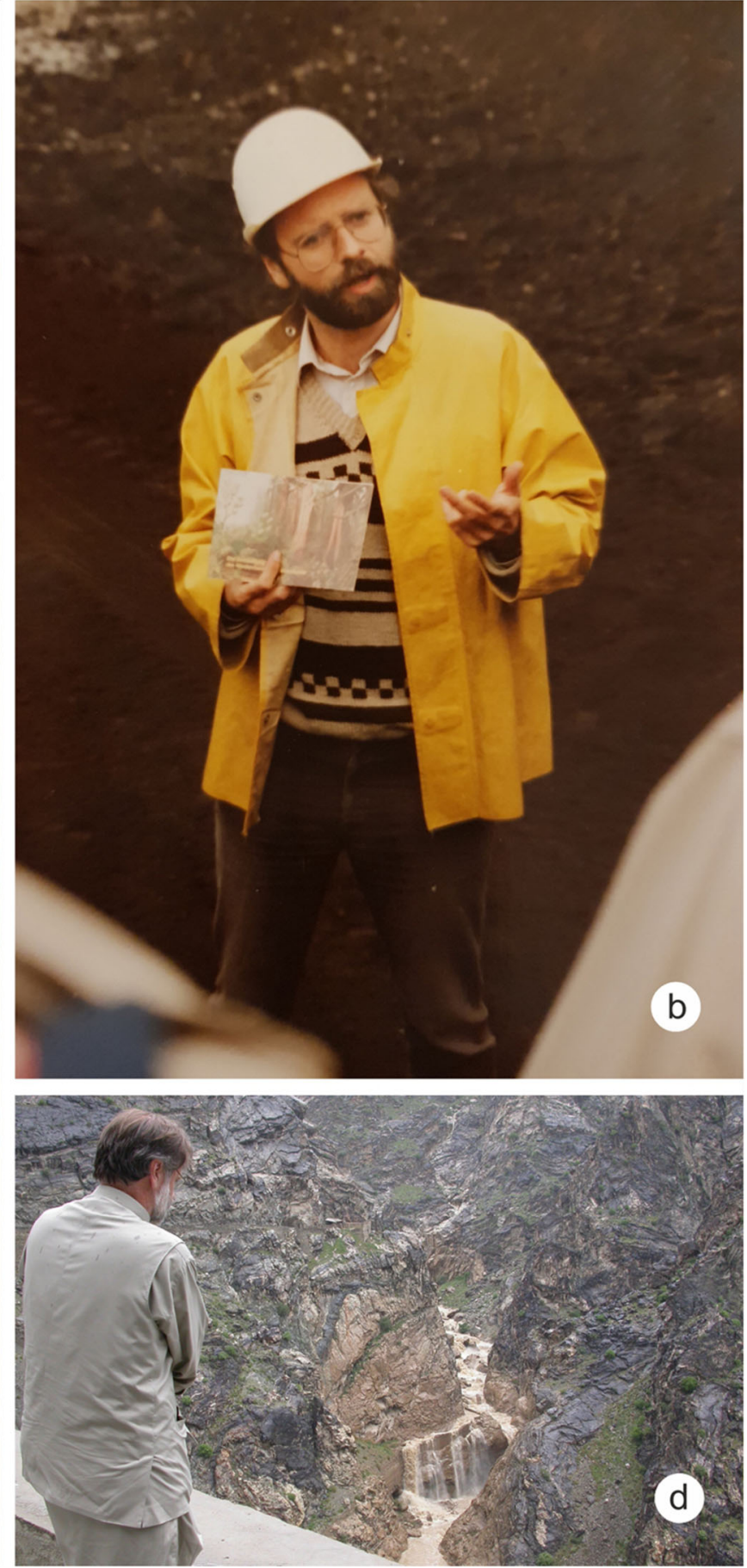

Mosbrugger); d Mahipar hydropower plant at the Kabul River, Afghanistan, 2005 (photo: A. R. Ashraf)

In 1999, the DFG awarded Volker the Gottfried Wilhelm Leibniz Prize, the most prestigious Science award in Germany. In the same year, another important step was the initiation of the NECLIME (Neogene Climate Evolution in Eurasia) network. Bringing together scientists from currently 34 countries, this network is still running with excellent 

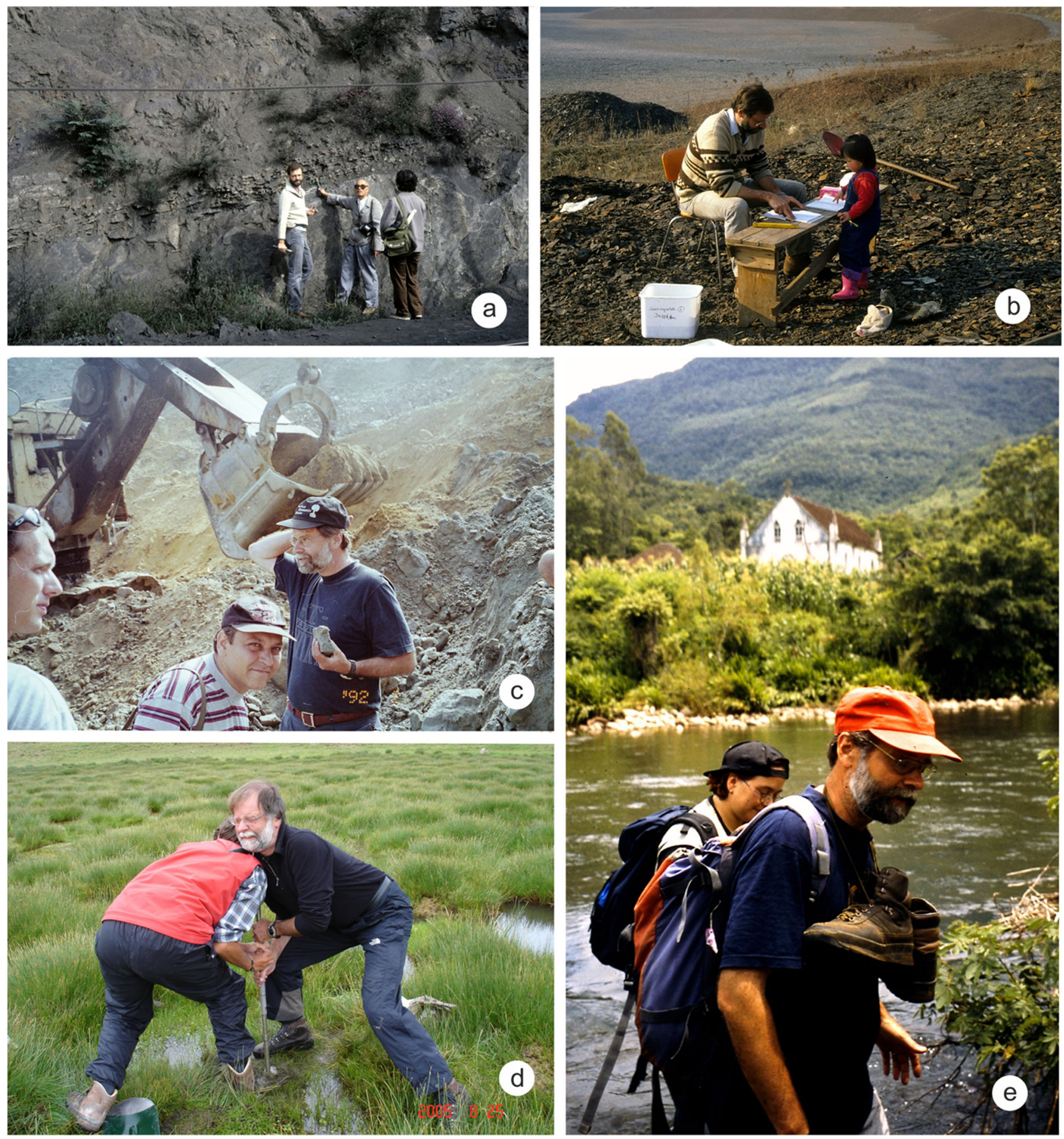

Fig. 2 Fieldwork. a Baode with Cai Chongyang, China, 1986 (photo: unknown); b UNESCO-world heritage Messel fossil pit with assistant (his daughter Jana), 1991 (photo: G. Mosbrugger); c Bulgaria with

success and so far six special issues summarising the results of this multi-national cooperation project have been published in different leading journals. During the last 20 years, more than 420 scientific articles with datasets on Neogene climate and environments became available by this network, documenting the high relevance of this international research network for
Dimiter Ivanov (centre) and Jörg Pross (left), 2000 (photo: A. R. Ashraf); d coring in Tibet, 2005 (photo: Lü Xinmiao); e Rio Grande do Sul, Brazil, 2001 (photo: A. R. Ashraf)

scientists working on Cenozoic climate evolution and related changes of continental ecosystems.

The year 2005 brought a big change for Volker, when he left Tübingen to become Director (since 2009 Director General) of the renowned Senckenberg Society for Natural Sciences in Frankfurt (Fig. 3). Although this step meant reducing his time 

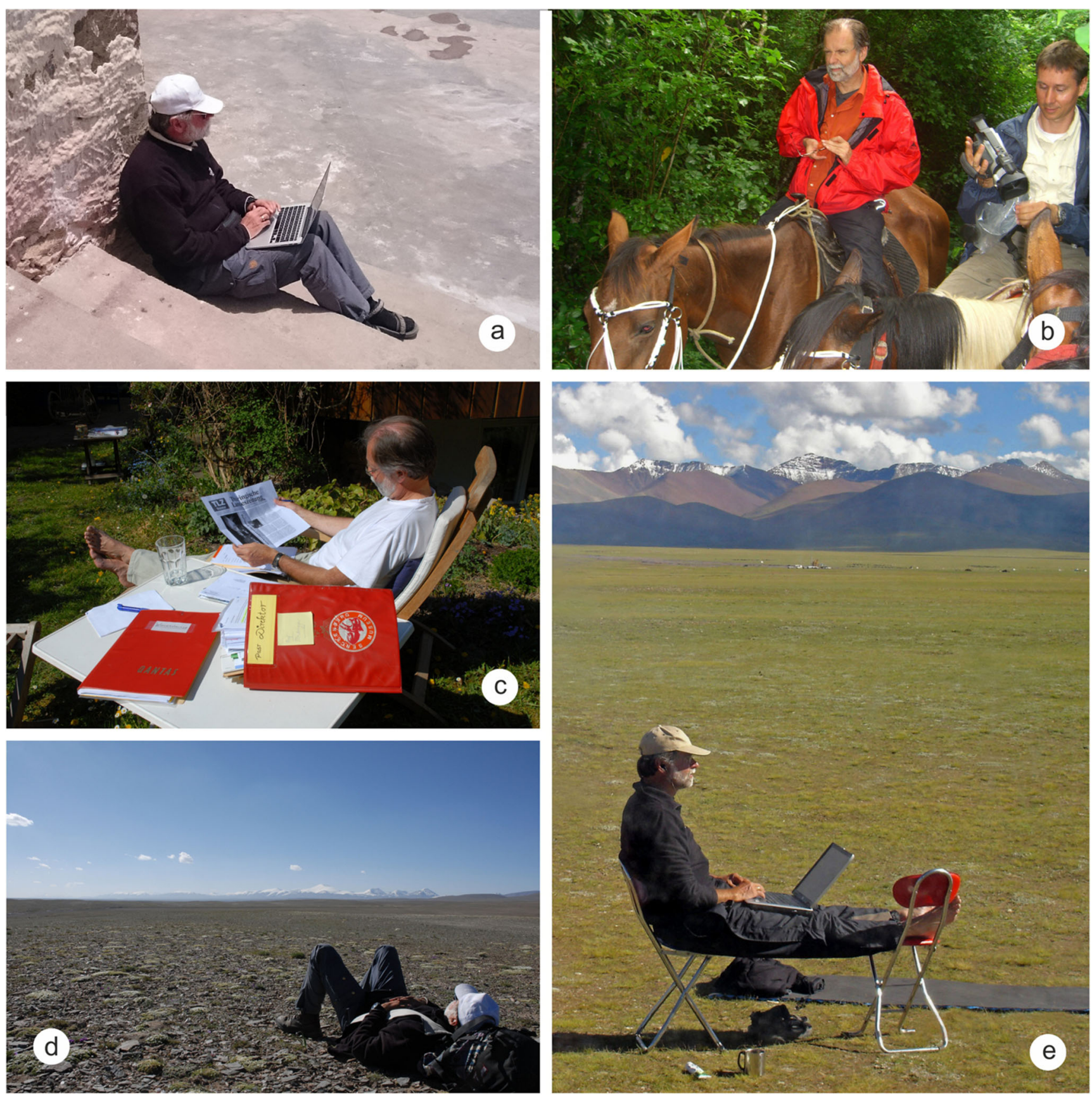

Fig. 3 Fieldwork as Director General. a Tibet, 2015 (photo: G. Mosbrugger); b Bolivia on horseback, 2007 (photo: S. Schaal); c in his garden doing his mail, 2006 (photo: G. Mosbrugger); d Tibet, 2015 (photo: G. Mosbrugger); e Tibet, 2005 (photo: Lü X.)

for actual research, it enabled Volker to flourish as a facilitator and communicator of science. Amongst his biggest successes during his time with Senckenberg, at least from a scientific point of view, are probably the establishment of the "Senckenberg Biodiversity and Climate Research Centre" (S-BiKF) in Frankfurt and the integration of the "Senckenberg Centre for Human Evolution and Palaeoenvironment at Tübingen University" (S-HEP) into Senckenberg.

With his distinct sense to create synergy, Volker Mosbrugger (as academician) successfully initiated the multidisciplinary research centre "The Role of Culture in Early Expansions of Humans" (ROCEEH) of the Heidelberg Academy of Sciences and Humanities co-directed with Nicolas Conard (S-HEP), Friedemann Schrenk (SF) and Volker Hochschild (University of Tübingen). The aim of this longterm project (funded for 2008-2027) is to generate a systemic understanding of "becoming human" by focusing on the development of the human capacity for cultural activities, as well as its environmental background and characteristics for the last three million years (Haidle et al. 2010, 2020). 

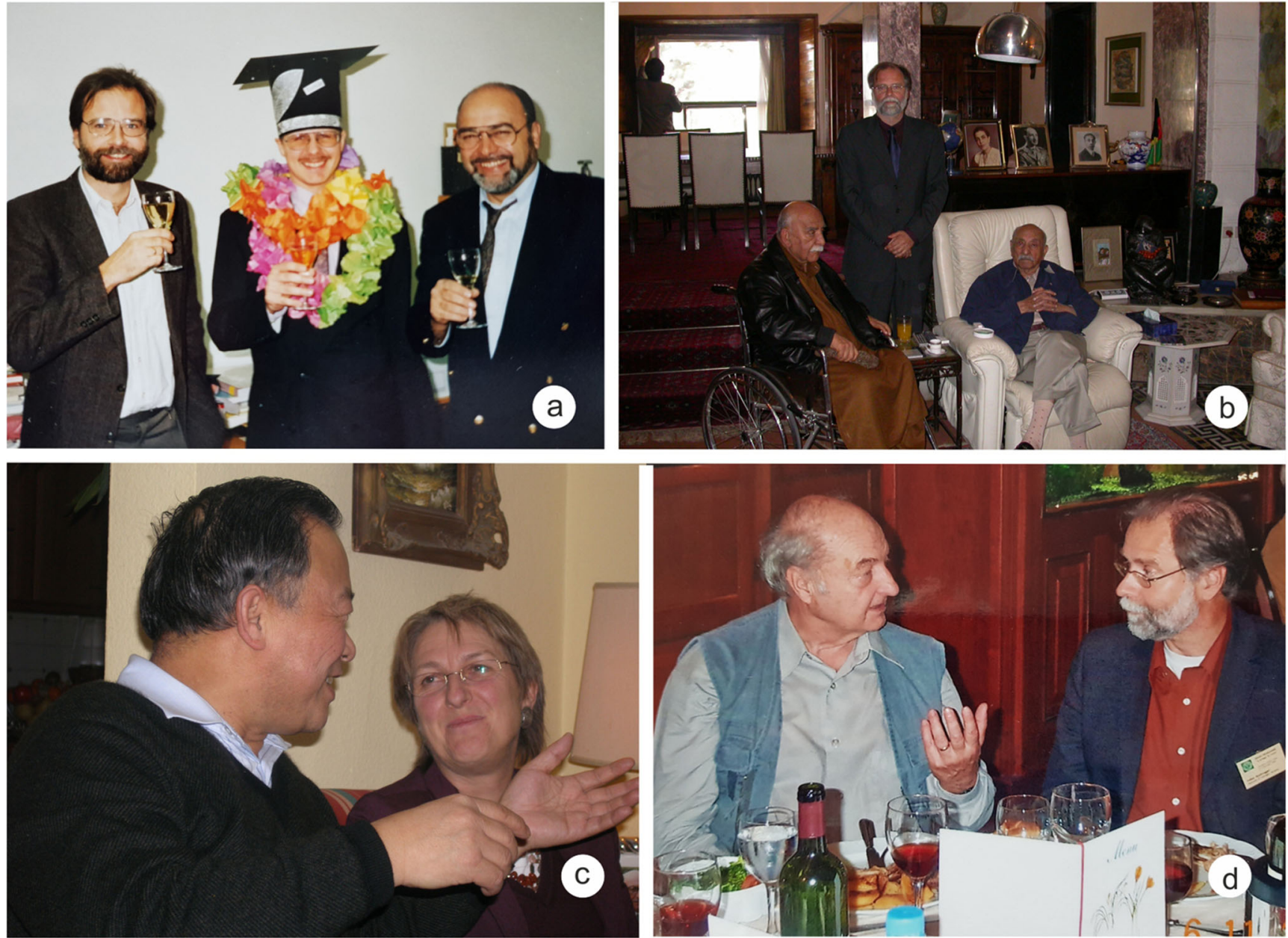

Fig. 4 People. a Volker Mosbrugger with Gerhard Belz, his first PhD student (centre) and his friend and colleague Abdul Rahman Ashraf (right), 1993 (photo: G. Mosbrugger); b audience with King Zahir Shah Father of the Nation in the Arg Palace, Kabul, Afghanistan, 2005 (photo: A. R. Ashraf); c Hechingen, Germany, Sun Ge (left), long-term

In the last decades, the Tibetan Plateau and the Himalayas became an important regional focus of Volker's research (e.g. Lü et al. 2020). Volker initiated and (co-)led several large national and international projects and programmes dealing with this region. Currently, he is one of the co-leaders of the international Third Pole Environment (TPE) programme, which he initiated together with Yao Tandong (Institute of Tibetan Plateau Research, Chinese Academy of Sciences) and Lonnie G. Thompson (Byrd Polar Research Center at The Ohio State University) in 2009. This programme has been endorsed by the UNESCO as a flagship programme.

Besides these main topics, Volker worked and published on a variety of other topics like palaeo-wildfires (e.g. Figueiral and Mosbrugger 2000) and several aspects of Mesozoic vegetation and climates (e.g. Ashraf et al. 2010). The latter was mostly connected to a long and fruitful scientific cooperation with Chinese colleagues from various universities and museums, going back to his time at Bonn University. cooperation partner, and the most important person: Gabi Mosbrugger (right), 2002 (photo: A. R. Ashraf); d with the late Zlatko Kvaček (1937-2020), one of the taxonomic pillars of the NECLIME network (photo: G. Mosbrugger)

Since 1981, Volker authored or co-authored more than 200 scientific papers or chapters on a wide variety of topics. Additionally, he published numerous items (reaching from small articles to entire books) for the general public as well as for decision makers, which span an even wider variety of topics. Listing all these publications would definitely go beyond our scope. So far, Volker successfully supervised 20 $\mathrm{PhD}$ students on various subjects at the Universities of Bonn, Tübingen, and Frankfurt/Main, as well as numerous diploma and master theses. He initiated and cultivated not only extensive scientific networks and co-operations but also advanced the dialogue between science, politics and society (Fig. 4). And although he is now retired since a few months (Fig. 5), he is still engaged in a number of projects that will certainly keep him busy for the next years.

The scientific papers compiled in this special issue mirror, at least to some degree, the different topics that dominated Volker's scientific career: 


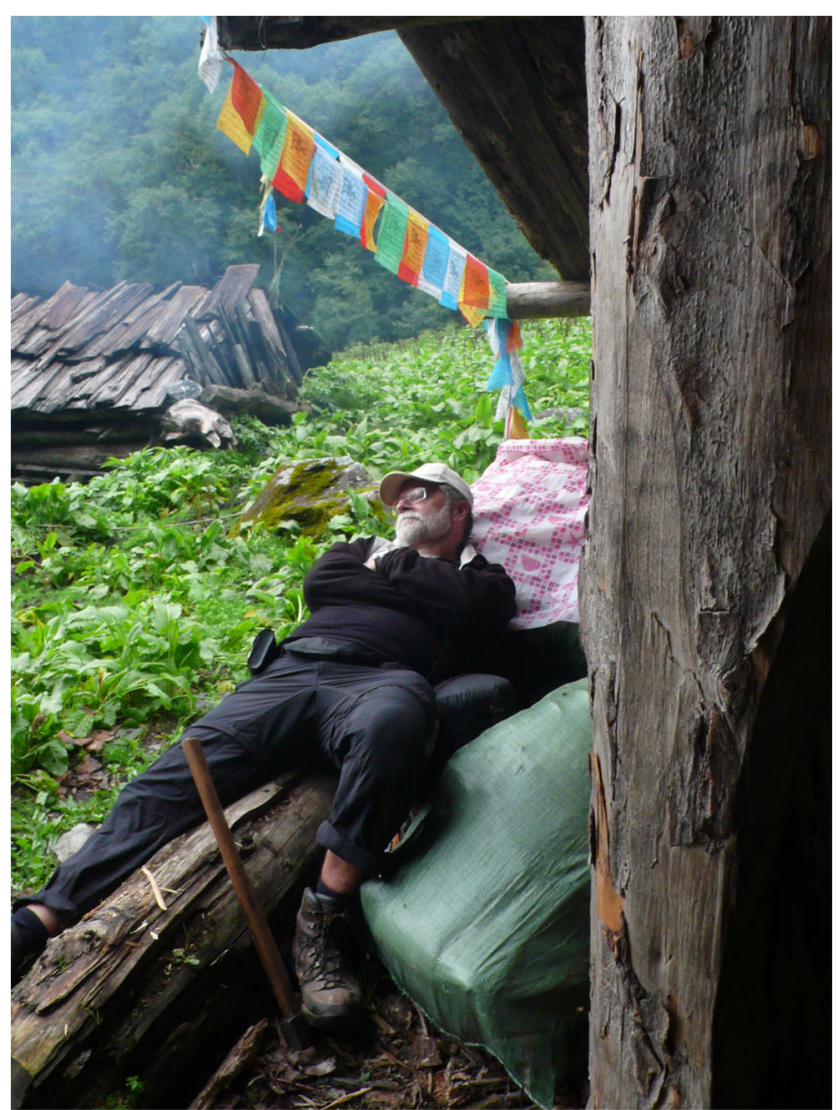

Fig. 5 Volker Mosbrugger in 2014 in Yunnan, dreaming of his retirement? Maybe, maybe not... (photo: G. Mosbrugger)

Uhl and Jasper (2021) analyse charcoal from clastic sediments and coals of the "Illinger Flözzone" (HeusweilerFormation; "Stephanian B", Kasimovian - Ghzelian) in the Saar-Nahe Basin (SW-Germany). Charcoal, as direct evidence for the occurrence of wildfires, is widespread in many Late Palaeozoic ecosystems. This charcoal, which most likely originates from Cordaitaleans, provides the first evidence for the occurrence of such wildfires during this period in the intramontaneous Saar-Nahe Basin. (Palaeobiodiversity and Palaeoenvironments 101(1) https://doi.org/10.1007/s12549020-00443-2)

Sun et al. (2021) provide new data on ferns, including sphenophytes, from the Middle Jurassic Baiyanghe section in the Junggar Basin in Xinjiang, NW China. This paper is a contribution to the joint Sino-German research on this basin, led by Volker Mosbrugger and Sun Ge, which has already been running for over 20 years. (Palaeobiodiversity and Palaeoenvironments 101(1) https://doi.org/10.1007/s12549020-00472-x)

Ma et al. (2021) report the occurrence of Sequoia jeholensis in the Middle Jurassic Jiulongshan Formation of Inner Mongolia, China. The determination is based on the morphology of leafy shots, as well as on cuticles, which are described for the first time. $S$. jeholensis represents the oldest species of this genus known so far. Based on the species assemblage, the authors interpret the climatic conditions, under which this taxon grew, as warm and humid, comparable to the demands of modern Sequoia sempervirens. (Palaeobiodiversity and Palaeoenvironments 101(1) https://doi.org/10.1007/ s12549-020-00454-z)

EI Atfy (2021) carried out a palynological analysis of samples from three Cretaceous formations (Hauterivian to Santonian) collected from Faghur Hj5-1 well, north Western Desert, Egypt. Palynofacies results allow the reconstruction of depositional environment, thermal maturity and kerogen types, providing substantial data on the exploratory values of the studied formations. (Palaeobiodiversity and Palaeoenvironments 101(1) https://doi.org/10.1007/s12549-020-00474-9)

Uhl et al. (2021) describe a minute flower with in situ pollen tetrads from the Paleocene Fossillagerstätte Menat (Puy-de-Dôme) in France. This heptamerous flower bears pollen tetrads in its anthers which resemble pollen tetrads of the modern Ericacean genus Kalmia. The new taxon Menatanthus mosbruggeri gen. nov. et sp. nov. is named in honour of Volker Mosbrugger. (Palaeobiodiversity and Palaeoenvironments 101(1) https://doi.org/10.1007/s12549-020-00453-0)

Erdei and Hably (2021) describe winged seeds from the Karpatian (late early Miocene) Feked Formation and Komló Claymarl Member at the locality Magyaregregy in the Mecsek Mountains in W Hungary. These seeds are compared with serval fossil and modern genera from several families. The specimens seem to be best comparable with species of Gordonia J. Ellis (s.l.,), based on their overall morphology and surface patterns. The authors erect the new taxon Mecsekispermum gordonioides Hably and Erdei gen. nov. et sp. nov., tentatively related to Theaceae. (Palaeobiodiversity and Palaeoenvironments 101(1) https://doi.org/10.1007/ s12549-020-00461-0)

Ivanov and Belkinova (2021) describe the new fossil species Closterium mosbruggeri sp. nov., a unicellular, desmidian algae belonging to the charophyta, from the Middle Miocene of Northwest Bulgaria. The new species is named in honour of Volker Mosbrugger. (Palaeobiodiversity and Palaeoenvironments 101(1) https://doi.org/10.1007/ s12549-020-00476-7)

Kvaček (2021) describes a new fossil fruit of the Styracaceaen genus Halesia L. from the Bohemian Miocene (Czech Republic). The new taxon Halesia mosbruggeri, sp. nov. is named in honour of Volker Mosbrugger. (Palaeobiodiversity and Palaeoenvironments 101(1) https:// doi.org/10.1007/s12549-020-00463-y)

Ivanov et al. (2021) investigated Late Miocene sediments from the Beli Breg Coal Basin, Western Bulgaria. The fossil pollen flora provides insights in the dynamics and development of the vegetation in the studied basin. Quantitative 
climate data reconstructed using the Coexistence Approach indicate a warm and humid climate, with low seasonality and a relatively short dry period, favourable for the distribution of warm-temperate mixed mesophytic forest vegetation. (Palaeobiodiversity and Palaeoenvironments 101(1) https:// doi.org/10.1007/s12549-020-00475-8)

Srivastava et al. (2021) provide a quantitative reconstruction of the palaeoclimate of the Upper Siwalik subgroup (Late Pliocene-Early Pleistocene) in the eastern Himalayan region, using the Coexistence Approach (CA) applied to fossil macrofloras (leaves, wood, and fruits). The reconstructed data indicate a monsoonal climate with strong seasonality. Moreover, the results point to a shift from dominantly wet evergreen to semi-evergreen vegetation, probably reflecting an increase in the length of the dry season. (Palaeobiodiversity and Palaeoenvironments 101(1) https://doi.org/10.1007/s12549-02000457-w)

Sciumbata et al. (2021) contribute to the understanding of the history of biodiversity in Amazonia by linking a statistical approach to detect a connection between Miocene marine incursions and their effect on the biogeography of the fossil pollen flora and modern biodiversity. This concept is supported by detailed pollen morphological studies of selected mangrove taxa to attribute botanical affinities to fossil morphotypes. (Palaeobiodiversity and Palaeoenvironments 101(1) https://doi.org/10.1007/s12549-020-00470-z)

Ghosh et al. (2021) execute a quantitative palaeoclimatic reconstruction with the Coexistence Approach, based on 20 Late Miocene to Early Pleistocene wood floras of the Bengal Basin. The detected weakening of Indian Summer Monsoon since the Early Pleistocene correlates with the global cooling trend, though with spatial differences. A comparison with published records from other sites provides further insights into the temporal and spatial patterns of climate evolution in southern Asia during the late Neogene-Quaternary transition. (Palaeobiodiversity and Palaeoenvironments 101(1) https:// doi.org/10.1007/s12549-020-00467-8)

Liu et al. (2021) analyse palynological samples from the Xialafudie Formation in the west Kunlun region (China), at the northern margin of the Tibetan Plateau. Combined with macrobotanical evidence, the work puts the Xialafudie Formation into a new stratigraphic framework and concludes a Pliocene age. The pollen data indicate a dry and cold environment, and together with published records from this region, clearly show an intensification of Central Asian aridification during the Pliocene, as a result of long-term global cooling and regional tectonics. (Palaeobiodiversity and Palaeoenvironments 101(1) https://doi.org/10.1007/s12549020-00458-9)

Allstädt et al. (2021) present a study on Late Pliocene to Early Pleistocene climate dynamics in western North America based on a new pollen record from paleo-Lake Idaho. Quantitative pollen-based climate estimates, using probability density calculations, reveal glacial/interglacial cycles at orbital scale (obliquity), with partial expansion of steppe vegetation during the cold phases. A major shift in the forest vegetation is reported for 2.6 Ma referable to an enhanced moisture transport from the northern Pacific. (Palaeobiodiversity and Palaeoenvironments 101(1) https://doi.org/10.1007/s12549020-00460-1)

Popescu et al. (2021) report on the Late Quaternary vegetation and climate change of SE Europe/Asia Minor based on pollen records of three cored wells from the Black and Marmara Seas. Using the Probability Mutual Climatic Spheres (PCS) technique and synthesised pollen diagrams the authors provide detailed, quantitative records of major regional climate and vegetation changes from the LGM to the Atlantic period. (Palaeobiodiversity and Palaeoenvironments 101(1) https:// doi.org/10.1007/s12549-020-00464-x)

Spicer et al. (2021) provide a review of isotopic and fossil proxies for palaeoaltometry from the Tibetan region to build a new model for the Paleogene topographical development of the Tibet region. The data presented by the authors demonstrate that the widely used, simplistic concept of 'the uplift of the Tibetan Plateau' as a single topographic entity is not in agreement with these proxies. Based on their review, the authors establish a new pattern for the topographic and landscape evolution of this region. (Palaeobiodiversity and Palaeoenvironments 101(1) https://doi.org/10.1007/s12549-020-00452-1)

Sun et al. (2021) evaluate the palaeoenvironmental significance of phytoliths and pollen based on modern surface-soil samples from the Xilingol Grassland, Inner Mongolia, North China. This case study will help future works on fossil grassland ecosystems, and stresses the importance of multiproxy analyses to improve palaeovegetation and palaeoclimate reconstructions. (Palaeobiodiversity and Palaeoenvironments 101(1) https://doi. org/10.1007/s12549-020-00473-w)

Fortelius et al. (2021) conduct a philosophical discussion on core assumptions of functional vs. taxonomical approaches (here Coexistence Approach) used for quantitative palaeoclimate reconstruction. The Coexistence Approach, having a relatively strong historical component, compared to techniques based on morphological traits, is brought in connection to Leibniz' evolutionary thinking. (Palaeobiodiversity and Palaeoenvironments 101(1) https://doi.org/10.1007/s12549-020-00468-7)

Roth-Nebelsick et al. (2021) provide an overview of how the functional morphology of trees can connect plant biology, evolution, and physics. The authors approach functional morphology and biomechanics of trees from various perspectives and discuss the complex interrelationships between traits, functionality and phylogeny. The paper underlines the importance of tree function analysis involving a wide range of applications, while the main focus is on the physics of plant water transport and plant-atmosphere interactions. (Palaeobiodiversity and Palaeoenvironments 101(1) https://doi.org/10.1007/s12549020-00466-9) 
Acknowledgements Firstly, we thank Volker for decades of scientific cooperation and inspiration. We also thank all the friends and colleagues who contributed to this special issue, either as authors, or as reviewers. Furthermore, we thank Volker's and our long-term friend Abdul Rahman Ashraf (Bonn, Germany) and Volker's wife Gabi Mosbrugger (Frankfurt/ Main, Germany) for providing photographs and information. Last but not least, we thank Peter Königshof and Sinje Weber for supporting our proposal to publish this Special Issue of Palaeobiodiversity and Palaeoenvironments and for their invaluable help during all phases of this project.

Funding Open Access funding enabled and organized by Projekt DEAL.

\section{Declarations}

Conflict of interest The authors declare that they have no conflict of interest.

Open Access This article is licensed under a Creative Commons Attribution 4.0 International License, which permits use, sharing, adaptation, distribution and reproduction in any medium or format, as long as you give appropriate credit to the original author(s) and the source, provide a link to the Creative Commons licence, and indicate if changes were made. The images or other third party material in this article are included in the article's Creative Commons licence, unless indicated otherwise in a credit line to the material. If material is not included in the article's Creative Commons licence and your intended use is not permitted by statutory regulation or exceeds the permitted use, you will need to obtain permission directly from the copyright holder. To view a copy of this licence, visit http://creativecommons.org/licenses/by/4.0/.

\section{References}

Ashraf, A. R., Yuewu, S., Ge, S., Uhl, D., Mosbrugger, V., Jie, L., \& Herrmann, M. (2010). Triassic and Jurassic palaeoclimate development in the Junggar Basin, Xinjiang, Northwest China - a review and additional lithological data. In T. Martin, G. Sun, \& V. Mosbrugger (Eds.) Triassic-Jurassic biodiversity, ecosystems, and climate in the Junggar Basin, Xinjiang, Northwest China. Palaeobiodiversity and Palaeoenvironments, 90(3), 187-201.

Figueiral, I., \& Mosbrugger, V. (2000). A review of charcoal analysis as a tool for assessing Quaternary and Tertiary environments: achievements and limits. Palaeogeography, Palaeoclimatology, Palaeoecology, 164, 397-407.
Haidle, M. N., Bolus, M., Bruch, A. A., Hertler, C., Kandel, A., Märker, M., Conard, N. J., Hochschild, V., Schrenk, F., \& Mosbrugger, V. (2010). The role of culture in early expansions of humans - a new research center. Quaternary International, 223-224, 429-430.

Haidle, M. N., Bolus, M., Bruch, A. A., Hertler, C., Hochschild, V., Kanaeva, Z., Sommer, C., \& Kandel, A. W. (2020). Human origins - digital future, an International Conference about the Future of Archaeological and Paleoanthropological Databases. Evolutionary Anthropology, 2020, 1-4.

Lü, X., Paudayal, K. N., Uhl, D., Liping, Z., Tandong, Y., \& Mosbrugger, V. (2020). Phenology and climatic regime inferred from airborne pollen on the northern slope of the Qomolangma (Everest) region. Journal of Geophysical Research - Atmospheres, 125(24), e2020JD033405 (19 pp.).

Mosbrugger, V. (1983). Organic relationship of 2 fossil taxa as a taxonomic problem, exemplified by the Late Paleozoic fern fructifications Scolecopteris and Acitheca. Review of Palaeobotany and Palynology, 40, 191-206.

Mosbrugger, V. (1988). Makroevolution aus botanisch-paläobotanischer Sicht. Eclogae Geologicae Helvetiae, 81, 905-909.

Mosbrugger, V. (1990). The tree habit in land plants: a functional comparison of trunk constructions with a brief introduction into the biomechanics of trees. Lecture Notes in Earth Sciences, 28161 p.

Mosbrugger, V., \& Utescher, T. (1997). The coexistence approach - a method for quantitative reconstructions of Tertiary terrestrial palaeoclimate data using plant fossils. Palaeogeography, Palaeoclimatology, Palaeoecology, 134, 61-86.

Mosbrugger, V., \& Vogellehner, D. (1986). Systematisch-taxonomische und phylogenetische Untersuchung der Pecopteriden -Taphoflora an der Hohengeroldseck bei Lahr (Mittlerer Schwarzwald). Palaeontographica Abteilung B-Palaeophytologie, 199, 91-192.

Roth-Nebelsick, A., Uhl, D., Mosbrugger, V., \& Kerp, H. (2001). Evolution and function of leaf venation architecture: a review. Annals of Botany, 87, 553-566.

Steppuhn, A., Micheels, A., Geiger, G., \& Mosbrugger, V. (2006). Reconstructing the Late Miocene climate and oceanic heat flux using the AGCM ECHAM4 coupled to a mixed-layer ocean model with adjusted flux correction. Palaeogeography, Palaeoclimatology, Palaeoecology, 238, 399-423.

Utescher, T., Bruch, A. A., Erdei, B., Francois, L., Ivanov, D., Jacques, F. M. B., Kern, A. K., Yu-Sheng, L., Mosbrugger, V., \& Spicer, R. A. (2014). The Coexistence Approach - theoretical background and practical considerations of using plant fossils for climate quantification. Palaeogeography, Palaeoclimatology, Palaeoecology, 410, 58-73.

Publisher's note Springer Nature remains neutral with regard to jurisdictional claims in published maps and institutional affiliations. 